\title{
3A: When and who to give anti-H. pylori treatment
}

\section{A:01 MAINTENANCE THERAPY WITH RANITIDINE ENHANCES REINFECTION WITH H. PYLORI AFTER SUCCESSFUL ERADICATION}

G. Manes ${ }^{1,2}$, J.E. Dominguez-Munoz ${ }^{2}$, G. Uomo ${ }^{1}$, T. Gigliotti ${ }^{1}$ ${ }^{1}$ Cardarelli Hosp., Napoli, Italy; ${ }^{2}$ University Magdeburg, Germany

Long term inhibition of gastric acid secretion for ulcer disease is still a frequent therapeutical approach, even after a successful $H$. pylori eradication, in patients who still report dyspeptic symptoms. Aim of the study was to analyze whether this therapy influences the rate of $H$. pylori reinfection and ulcer recurrence after successful eradication. Patients and methods: $66 \mathrm{pa}-$ tients with duodenal ulcer and $H$. pylori associated gastritis were randomly assigned to a 12 months maintenance treatment with ranitidine $150 \mathrm{mg}$ daily (group A) and no treatment (group B), after successful eradication (amoxicillin $1 \mathrm{~g}$ b.i.d. and omeprazole $40 \mathrm{mg}$ b.i.d. for 14 days). Follow-up consisted of clinical and endoscopic controls with biopsies (histology for antrum and corpus, rapid urease test for antrum) every 4 months for 1 year or more often if indicated by symptoms. Results: 6 patients, 3 for each group, were lost at follow up. H. pylori reinfection occurred in 9 patients of group A (30\%) (in 6 after 8 months and 3 after 12 months) and in 2 patients of group B (7\%, p < 0.05) (after 8 and 12 months respectively). Duodenal ulcer recurred in one patients of group A (3\%) and in 2 of group B $(7 \%$, n.s.), all three patients showing a $H$. pylori reinfection. Erosive duodenitis was observed in further two cases of group $A$. In all reinfected patients of group A but in none of B we observed a corpus predominant gastritis in term of activity and chronicity scores. Conclusion: Long term treatment with ranitidine enhances $H$. pylori reinfection after successful eradication. These data support the hypotesis that gastric acidity not only influences the pattern of $H$. pylori localization in gastric mucosa, but also play a role in preventing gastric infection and/or in completing $H$. pylori elimination after an antimicrobial treatment.

\section{A:02 OPEN QUESTIONS OF H. PYLORI ERADICATION THERAPY IN THE TREATMENT OF PRIMARY CARE PATIENTS FROM LESS DEVELOPED COUNTRIES}

W. Dohmen, R.E.A. Seelis. Thomashoftstr. 3, 52070 Aachen

For western countries there are ample data to support antimicrobial eradication of $\mathrm{H}$. pylori (Hp) infection in patients with peptic ulcer disease. However fundamental questions remain concerning the initial evaluation and treatment of primary care patients from less developed countries. In Germany foreign workers immigrated from Turkey are representing 3-10\% of family doctor patients. We analyzed data of our unselected consecutive gastroscopied general practice patients complaining upper abdominal pain. Hp status from european as well as from turkish patients was detected by urease test ( $n=1227$ patients) and histology ( $n=337$ patients). Hp positive individuals revealing gastric/duodenal ulcer or relapsing erosive gastritis underwent eradication therapy using a very effective 6 days triple therapy recently published by our group (pantoprazol $40 \mathrm{mg}$ bd + azithromycin $500 \mathrm{mg}$ bd + tinidazol $1000 \mathrm{mg}$ bd).

\begin{tabular}{|c|c|c|c|c|c|c|}
\hline$\overline{\text { Patients }}$ & $\begin{array}{l}\text { Hp positive } \\
\text { patients }\end{array}$ & $\begin{array}{l}\text { Patients } \\
\text { with ulcer }\end{array}$ & $\begin{array}{l}\text { Hp therapy } \\
\text { (patients) }\end{array}$ & $\begin{array}{l}\text { Patient age } \\
\text { (years) }\end{array}$ & $\begin{array}{l}\text { Pain relief } \\
\text { (days) }\end{array}$ & $\begin{array}{l}\text { H. pylori- } \\
\text { eradication }\end{array}$ \\
\hline $\begin{array}{l}\text { Europeans } \\
(n=1161)\end{array}$ & $47.1 \%$ & $9.4 \%$ & $n=40$ & $50.4 \pm 13.5$ & $2.6 \pm 0.8$ & $95.0 \%$ \\
\hline $\begin{array}{l}\text { Turkish } \\
(\mathrm{n}=72)\end{array}$ & $84.8 \%$ & $30.3 \%$ & $n=33$ & $46.9 \pm 7.7$ & $3.4 \pm 1.3$ & $54.5 \%$ \\
\hline
\end{tabular}

$6 \%$ of our patients were of turkish origin. Hp infection rate of these patients exceeded those of Europeans almost by $38 \%$. Additionally peptic ulcer rate was higher in turkish than in european Hp positive individuals (30.3 vs $9.5 \%$ ). Finally, Hp eradication rates of turkish were more than $40 \%$ lower compared to european patients. In both age and smoker $(50.0$ vs $54.3 \%$ ) matched groups compliance did not play a major role. Our data reveal that further studies on the role of Hp eradication in the primary care management of peptic ulcer disease are needed, particularly in populations not well studied to date.

\section{A:03 DOES DISEASE PRESENTATION INFLUENCE TREATMENT OF HELICOBACTER PYLORI INFECTION? A NATIONWIDE COMPARISON OF GASTROENTEROLOGISTS AND FAMILY PRACTITIONERS IN THE UNITED STATES OF AMERICA}

T. Breuer ${ }^{1,2}$, H.M. Malaty ${ }^{1}$, K. Goodman ${ }^{2}$, T. Sudhop ${ }^{3}$, D.Y. Graham ${ }^{1}$. ${ }^{1}$ VA Medical Center, Baylor College of Medicine, Germany; ${ }^{2}$ Univ. of Texas, School of Public Health, Houston, TX USA ${ }^{3}$ Univ. Bonn, Germany

Purpose: Little is known how practicing physicians in the US treat $H$. pylori related ulcer disease and other possible $H$. pylori-related diseases. In this study we compared treatment patterns of gastroenterologists (GEs) and family practitioners (FPs)

Methods: Nationwide cross-sectional study, mail questionnaire.

Results (to date): 648 GEs and 486 FPs responded as follows:

\begin{tabular}{lcc}
\hline Associated disease & \multicolumn{2}{c}{$\begin{array}{c}\text { Proportion that treat } \\
\text { diagnosed }\end{array}$} \\
\cline { 2 - 3 } & GEs pylori infection \\
\hline Uncomplicated DU (first presentation) & $98 \%$ & FPs \\
Uncomplicated DU (recurrent) & $100 \%$ & $99 \%$ \\
Uncomplicated GU (first presentation) & $97 \%$ & $92 \%$ \\
Uncomplicated GU (recurrent) & $100 \%$ & $98 \%$ \\
Nonulcer dyspepsia & $43 \%$ & $72 \%$ \\
All H.pylori positive cases & $24 \%$ & $65 \%$ \\
\hline
\end{tabular}

$\chi^{2}$ p-value $<0.001$ for all comparisons.

Conclusions: A very high percentage of physicians use antibiotics to treat recurrent $H$. pylori-positive gastroduodenal ulcer disease. $11 \%$ of the FPs still do not treat diagnosed $H$. pylori infection in the first presentation of duodenal ulcer disease. Our interpretation of these data is that new knowledge in the field of treatment of peptic ulcer disease is being widely disseminated via specialists to the general practitioners. Overall, FPs show less discrimination in relation to the nature of the illness. In particular, family practitioners use antibiotics to treat $72 \%$ of $\mathrm{H}$. pylori-positive patients with nonulcerative dyspepsia. To date, there is no convincing evidence that $H$. pylori infection causes nonulcerative dyspepsia. This pattern is confirmed on comparing the proportion who recommend antibiotic therapy for all $H$. pylori-positive patients regardless of the clinical profile, $65 \%$ of FPs versus $24 \%$ of GEs.

\section{A:04 SHOULD HELICOBACTER PYLORI STATUS BE} DETERMINED BEFORE INITIATING ERADICATION THERAPY IN CHRONIC DUODENAL ULCER DISEASE?

A.T. Prach ${ }^{1}$, B.W. Senior ${ }^{2}$, D. Hopwood ${ }^{3}$, P.D.P. McBride ${ }^{3}$, M.A. Kerr ${ }^{3}$, F.E. Murray ${ }^{1}{ }^{1}$ Departments of Clinical Pharmacology; ${ }^{2}$ Medical Microbiology; ${ }^{3}$ Pathology, University of Dundee, Ninewells Hospital and Medical School, Dundee, DDI 9SY, Scotland, UK

It has been suggested that establishing Helicobacter pylori $(\mathrm{Hp})$ infection status is irrelevant prior to $H p$ eradication treatment in chronic duodenal ulcer (DU), as virtually all may benefit from therapy. The aim of the present study was to determine the prevalence of active $H p$ infection in patients with proven chronic DU on long-term prophylactic treatment and whether knowledge of this would influence the use of eradication therapy.

Methods: 145 patients receiving long-term $\mathrm{H}_{2}$-antagonists for chronic DU were recruited. Their case records and a prescribing database were reviewed. Patients underwent endoscopy with biopsies for rapid urease test, histology and $H p$ culture. Serum was immunoblotted and an enzyme-linked immunosorbent assay for $H p$ was performed.

Results: Of the 145 patients, $128(88 \%)$ were $H p$ positive. Twelve of the $17 \mathrm{Hp}$ biopsy-negative patients had anti-Hp IgG antibodies and 10 of the $17 \mathrm{Hp}$-negative patients had previously received antibiotics for other indications. Nine patients were exposed to non-aspirin non-steroidal anti-inflammatory drugs and one had additional aspirin exposure.

Conclusion: Only $11.7 \%$ of patients on maintenance treatment for chronic DU had no current infection with $H p$, although $>70 \%$ had previous infection. Confirmation of active infection in this patient group may result in more precise targeting of eradication therapy and avoid unnecessary and potentially hazardous treatment. 
3A:05 MANAGEMENT OF PATIENTS WITH KNOWN DUODENAL ULCER DISEASE BUT UNKNOWN Hellicobacter PYLORI STATUS: A DECISION ANALYSIS

J.T. McCort, A.M. Fendrick. University of Michigan, Ann Arbor, MI, USA

Patients diagnosed with duodenal ulcer (DU) but not previously evaluated for $H$. pylori (HP) infection are at marked risk for ulcer recurrence. Given the high rate of HP infection in DU patients, successful HP eradication should reduce patient morbidity and lower health care expenditures.

We developed a computer simulation model to estimate clinical and economic effects of treatment alternatives for patients with unknown DU unrelated to non-steroidal drug use and unknown HP status. On entry to the model, patients were assumed to be without an active ulcer and free of symptoms. For patients not receiving maintenance anti-secretory therapy (MT) we evaluated two strategies: 1) expectant management (evaluation and treatment of HP infection only when symptoms occurred) and 2) immediate empiric HP eradication therapy. The two treatment strategies evaluated for patients receiving MT were: 1) continuation of MT (HP therapy reserved for when symptoms occurred) and 2) immediate empiric HP eradication therapy. Clinical inputs were derived from published literature. Cost estimates were based on actual payments from third party payers.

The estimated costs per patient and ulcer recurrence rates by management strategy for one year were :

\begin{tabular}{lll}
\hline & \$/patient & DU recur rate \% \\
\hline No maintenance anti-secretory therapy on entry & & \\
Expectant management & $\$ 359$ & 57 \\
Immediate empiric HP eradication treatment & $\$ 476$ & 15 \\
Maintenance anti-secretory therapy on entry: & & \\
Continue maintenance anti-secretory therapy & $\$ 752$ & 19 \\
Immediate empiric HP eradication treatment & $\$ 476$ & 15 \\
\hline
\end{tabular}

At one year the model estimated that DU patients not initially taking MT who were empirically treated for HP had fewer DU recurrences but slightly higher costs than if HP eradication treatment was delayed until symptoms occurred. This cost differential would likely be reduced or potentially reversed if the duration of the model extended beyond one year. For those patients initially taking MT, prompt HT eradication led to both fewer DU recurrences and lower health care expenditures as ulcer complications, physician visits, and diagnostic tests were reduced and the need for MT diminished.

We conclude that the clinical outcomes of all patients with past documented DU can be improved with the prompt eradication of HP infection. The economic justification for such a strategy is clear for patients requiring maintenance anti-secretory therapy; advantages in resource utilization are likely to emerge in the long term for those patients not currently taking these agents.

\section{A:06 TREATMENT REGIMENS USED IN HELICOBACTER PYLORI POSITIVE ULCER DISEASE; A NATIONWIDE COMPARISON OF GASTROENTEROLOGISTS AND FAMILY PRACTITIONERS IN THE UNITED STATES OF AMERICA}

T. Breuer ${ }^{1,2}$, H.M. Malaty ${ }^{1}$, K. Goodman ${ }^{2}$, T. Sudhop ${ }^{3}$, D.Y. Graham ${ }^{1}$. ${ }^{1}$ VA Medical Center, Baylor College of Medicine, Houston, TX, USA;

${ }^{2}$ Univ. of Texas, School of Public Health, Houston, TX, USA; ${ }^{3}$ Univ. Bonn, Germany

Background: The literature provides a large variety of therapeutic regimens for treating $H$. pylori infection. The aim of this study was to determine the first line treatment used by two groups of physicians (gastroenterologists (GEs) and family practitioners (FPs)) in $\mathrm{H}$. pylori-positive ulcer disease.

Methods: Nationwide cross-sectional study, mail questionnaire.

Results (to date): 645 GEs and 480 FPs responded as follows:

\begin{tabular}{lll}
\hline Regimen & GEs \% $(\mathrm{n}=645)$ & FPs \% $(\mathrm{n}=480)$ \\
\hline PPI based triple & 36 & 14 \\
Standard triple & 16 & 25 \\
PPI based quadruple & 16 & 11 \\
PPI/CLA & 11 & 8 \\
H2 based quadruple & 9 & 10 \\
PPI/AMO & 4 & 5 \\
other & 8 & 26 \\
\hline
\end{tabular}

$\chi^{2}$ p-value $<0.001$ for overall comparison.

PPI (Proton pump inhibitor), AMO (Amoxicillin), $\mathrm{H}_{2}$ ( $\mathrm{H}_{2}$-inhibitors), CLA (Clarithromycin), MET (Metronidazole) BIS (Bismuth); PPI based triple (PPI plus combination of two antibiotics (AMO, CLA, MET); Standard triple (BIS, MET, TET/AMO), PPI based quadruple (PPI plus standard triple); $\mathrm{H}_{2}$ based quadruple $\left(\mathrm{H}_{2}\right.$ plus standard triple).

Based upon their cure rates, we graded the different regimens into three classes. A: State of the art regimen (consistent cure rates over 80\%.) B PPI/AMO (lower cure rate than A, less consistent). C: Regimens with known poor cure rate or unknown performance. Conclusion: The most effective $H$. pylori regimens (Category A) are used by a large proportion of GEs. In spite of this, $31 \%$ of the FPs vs. $12 \%$ of the GEs treat $H$. pylori positive ulcer disease with less effective or ineffective regimens. This study underlines that knowledge acquisition of newly recommended therapies for H. pylori infection is not optimal. Researchers in the field have to make sure that dissemination of currently recommended therapies is a continuous process.

\section{A:07 COST-IMPACT OF CLARITHROMYCIN PLUS OMEPRAZOLE COMPARED TO TRADITIONAL THEAAPIES FOR TREATMENT OF H. PYLORI ASSOCIATED DUODENAL ULCERS}

A. Sonnenberg. VA Medical Center, Albuquerque, NM; The Gastrointestinal Utilization Trial Study Group

Introduction: The NIH Consensus Development Conference recommended a comprehensive economic analysis of the impact of treating or not treating H. pylori (HP) associated ulcers. Patients were enrolled in a multicenter ( $n=132$ ), controlled clinical trial to determine cost savings of eradicating HP with clarithromycin plus omeprazole $(C+O)$ versus conventional anti-ulcer therapy (omeprazole $(\mathrm{O})$ or ranitidine $(\mathrm{R})$ alone). Methods: Adult patients with HP and active duodenal ulcer were randomized to double-blinded treatment (Rx): 1) C $500 \mathrm{mg}$ TID + $040 \mathrm{mg}$ QD for 14 days followed by $O 20 \mathrm{mg}$ OD for 14 days; 2) $O 20 \mathrm{mg}$ OD for 28 days; or 3) R $150 \mathrm{mg}$ BID for 28 days. Visits were performed at pre-Rx (EGD + biopsy), post-Rx (safety), and 4-6 weeks post-Rx (eradication). After the third protocol directed visit, investigators followed patients for one year by monthly telephone calls for assessment of ulcer symptoms and collection of economic data. Additional management was to be "standard of care" for that investigational site. Results: Of the 819 patients enrolled, 750 patients were eligible (confirmed ulcer and HP infection) for economic analysis. The demographics of the three groups were similar. Analysis of health resource utilization is given in the table below:

\begin{tabular}{lccc}
\hline $\begin{array}{l}\text { Resource Utilization } \\
\text { (beyond protocol) }\end{array}$ & $\begin{array}{l}\mathrm{C}+\mathrm{O} \\
(\mathrm{n}=253)\end{array}$ & $\begin{array}{l}\mathrm{O} \\
(\mathrm{n}=255)\end{array}$ & $\begin{array}{l}\mathrm{R} \\
(\mathrm{n}=242)\end{array}$ \\
\hline EGDs & 31 & 76 & 69 \\
Ulcer related clinic visits & 84 & 136 & 161 \\
Ulcer days lost from work & 116 & 122 & 787 \\
All hospitalizations & 26 & 47 & 42 \\
Ulcer related hospitalizations & 0 & 5 & 6 \\
All hospital days & 158 & 318 & 205 \\
Ulcer hospital days & 0 & 24 & 37 \\
\hline
\end{tabular}

While costs varied among the different centers, eradicating HP clearly led to a decrease in health care utilization.

Conclusion: Ours is the first prospective study to show that using antibiotics to eradicate $H$. pylori in patients with duodenal ulcer results in decreased utilization of health care resources, overall and ulcer related, when compared to conventional anti-ulcer therapy with omeprazole or ranitidine.

\section{A:08 SCREENING AND ERADICATION OF H. PYLORI INFECTION IN ADULT POPULATION OF VAMMALA, FINLAND}

A. Salomaa ${ }^{1}$, T.U. Kosunen ${ }^{2}$, H. Rautelin ${ }^{2}$, A. Aromaa ${ }^{3}$, P. Knekt ${ }^{3}$, O.P. Heinonen ${ }^{2} .{ }^{1}$ Vammala Health Center, Vammala, Helsinki, Finland; ${ }^{2}$ University of Helsinki, Helsinki, Finland; ${ }^{3}$ National Public Health Institute and Social Insurance Institution, Helsinki, Finland

As long as there is no vaccination, eradication of $\mathrm{H}$. pylori with antimicrobials remains the only direct way likely to lower the incidence of the infection in general population.

Our purpose was to study participation rates in and effectiveness of a population based pilot program aimed at this goal.

Methods. 967 subjects representing the local population aged 15 years and over living in Vammala city in 1994 were invited per mail to the study. Serum IgG and IgA antibodies to $\mathrm{H}$. pylori were determined by enzyme immunoassay and all antibody positive subjects were offered eradication therapy (first choise: amoxycillin $500 \mathrm{mg} \times 4$, metronidazole $400 \mathrm{mg} \times$ 3 and lanzoprazole $30 \mathrm{mg} \times 2$ daily for 14 days). Subjects older than 45 years of age were offered pretreatment endoscopy. All treated subjects were invited to serologic follow-up 6 months later. Urea breath test was used occasionally.

Results. 716 (74\%) of the invited subjects gave a blood sample. 269 (38\%) were antibody positive and $175(65 \%)$ of them attended clinical consultation. Of the $142 / 175(81 \%)$ who wanted treatment, 19 are still under investigation. 114/123 (93\%) subjects followed up for 6 months showed a diagnostic fall of antibodies; in four of those who did not, the presence of infection could not be confirmed by other tests (histology, culture or breath test). 
Conclusions. This pilot study on gastritis and helicobacters was carried out in a typical small Finnish city with both rural and urban population. Three fourths of the subjects invited participated in the serologic survey but only $51 \%$ of the infected subjects participated in the eradication program The initial seroprevalence of $38 \%$ in this group of adults aged 15 to 75 years was lowered to $22 \%$.

\section{A:09 A SURVEY ON THE MANAGEMENT OF HELICOBACTER PYLORI BY DUTCH SPECIALISTS}

P.J. Boekema ${ }^{1}$, G.P. van Berge Henegouwen ${ }^{1}$, R.A. Veenendaal ${ }^{2} .^{1}$ Dept. Gastroenterology-Hepatology, University Hospitals, Utrecht, The

Netherlands; ${ }^{2}$ Dept. Gastroenterology-Hepatology, University Hospitals, Leiden, The Netherlands

In a survey of the management of $H$. pylori infection a questionnaire was sent to 420 members of the Dutch Society of Gastroenterology in June 1995.

Of the 226 respondents (resp. rate 54\%) all but two treated patients for $H$. pylori infection. It could be estimated that at least one out of thousand Dutch inhabitants was treated for $H$. pylori infection in 1995 Indications for treatment of $H$. pylori were duodenal ulcer $(98 \%)$, gastric ulcer $(91 \%)$, low-grade B cell MALT lymphoma (56\%), pre-malignant changes in gastric mucosal histology $(33 \%)$, non-ulcer dyspepsia (32\%), and chronic use of PPI (30\%). The diagnostic methods used were histology (93\%), urease test $(60 \%)$, and culture (46\%). Most physicians (82\%) used a combination of tests. Non-invasive diagnostic tests were only used by a minority. Triple therapy was used for treatment by $54 \%$ of the respondents but the "classical" bismuth triple therapy (14\%) has been surpassed by proton pump inhibitor based triple therapies $(40 \%)$. The new quadruple therapy combination was used by $26 \%$ of the respondents. After treatment eradication of $H$. pylori was routinely confirmed by $42 \%$ of the respondents, while $48 \%$ only did so when clinically relevant. $72 \%$ of the respondents waited 8-12 weeks before testing for eradication.

In conclusion, treatment of $H$. pylori associated peptic ulcer disease was generally accepted. Diagnostic methods and treatment regimens, however, differed widely.

\section{A:10 IS THERE A CORRELATION BETWEEN THE MEAN VALUES OF IgG AND IgA SPECIFIC ANTIBODIES AGAINST H. PYLORI AND SEVERITY OF CHRONIC ACTIVE GASTRITIS?}

C. Martín de Argila, D. Boixeda, R. Cantón, C. Redondo, I. Baleriola, L.A. Gil, J.P. Gisbert, L. Moreno. "Ramón y Cajal" Hospital, Madrid, Spain

Aim: To evaluate the correlation between specific IgG and IgA values to $H$. pylori according to the severity of chronic active gastritis.

Methods: A total of 400 patients attended at the Endoscopy Unit because of symptoms attributable to the upper gastrointestinal tract were studied. At endoscopy, multiple biopsies from gastric antrum, gastric body, and gastric fundus were obtained for histology and $H$. pylori culture. The severity of chronic active gastritis was graded as mild, moderate and severe on the basis of polymorphonuclear leukocyte infiltration of gastric mucosa. It was not possible to determine the severity of chronic active gastritis in 7 patients. At endoscopy serum samples were obtained for serological testing. Specific IgG and IgA antibodies against $H$. pylori were determined by a quantitative commercial IgG ELISA (Helico G, Porton, Cambridge, UK) and a semiquantitative commercial IgA ELISA (G.A.P. Test IgA. Bio-Rad, Italy), respectively. $H$. pylori infection was diagnosed if culture was positive in at least one of the biopsy samples obtained.

Results: 355 out of 400 (89\%) patients were diagnosed with histological chronic gastritis involving some of the portion stomach. A total of 337 out of $355(95 \%)$ patients with histological chronic gastritis were infected by $H$. pylori (demonstrated by culture). Mean values of IgG and IgA specific antibodies against $H$. pylori in relationship to the chronic gastritis activity and the severity of gastritis in patients with gastritis yielded the following results:

\begin{tabular}{lrr}
\hline Chronic gastritis & \multicolumn{1}{c}{ IgG (U/ml) } & \multicolumn{1}{c}{$\operatorname{IgA}(\mathrm{U} / \mathrm{ml})$} \\
\hline Without activity & $69 \pm 38.6^{*}$ & $19 \pm 13.4$ \\
Mild activity & $77.4 \pm 44.5^{*}$ & $20.5 \pm 10.5$ \\
Moderate activity & $89 \pm 38.1$ & $27.8 \pm 22.3$ \\
Severe activity & $105.8 \pm 30.8$ & $53 \pm 69.1$ \\
\hline
\end{tabular}

$p<0.05$ in all comparisons between the different groups, with the exception of the comparison signed with "*”.

Conclusions: IgG and IgA specific antibodies against $H$. pylori mean values are clearly higher in patients with chronic gastritis with moderate and severe activity than those with chronic gastritis without activity. Moreover, mean values of IgG and particularly IgA specific antibodies against $H$. pylori $H$. pylori infection increased with increasing severity of chronic gastritis.
3A:11 PRELIMINARY REPORT ON THE FINANCIAL IMPLICATIONS OF TREATING PATIENTS WITH NON ULCER DYSPEPSIA (NUD) WITH ERADICATION THERAPY FOR HELICOBACTER PYLORI

K.U. Powell, G.D. Bell, A.F. Bowden, M. Brandon, P.H. Jones. Ipswich NHS Trust, Ipswich, England

160 patients with non ulcer dyspepsia (NUD) as assessed at OGD or Barium meal were asked to record prospectively their use of prescribed ulcer healing drugs (UHD), antacids and miscellaneous medicines for a 6 month period. 63 patients were known to be Helicobacter pylori positive (Hp +ve) as judged by $\mathrm{C} 14$ urea breath testing (BT) or on serology testing $(>6 \mu \mathrm{g} / \mathrm{l}$ ) by an Eliza technique. 97 patients had their Hp infection cleared at least 1 year prior to the study and were judged clear by follow up BT.

To date, the average cost of drugs consumed by the $\mathrm{Hp}+\mathrm{ve}$ patients was $£ 35$ per quarter compared with $£ 19$ for $\mathrm{Hp}$-ve patients. Consumption of UHD's accounted for $£ 28$ for $\mathrm{Hp}+\mathrm{ve}$ and $£ 16$ for $\mathrm{Hp}-\mathrm{ve}$ patients. Consumption of antacids and other gastric drugs was also lower in the $\mathrm{Hp}$ -ve group. Differences were noted in that if the patient had a hiatus hernia or gastro-oesophageal reflux disease (GORD) the costs were higher in both groups - $£ 42$ per quarter for $\mathrm{Hp}+\mathrm{ve}$ patients and $£ 32$ for $\mathrm{Hp}$-ve patients: compared with $£ 30$ for $\mathrm{Hp}+\mathrm{ve}$ patients and $£ 11$ for $\mathrm{Hp}$-ve patients if there was no evidence of GORD.

Differences were noted for male and female patients in each group. Costs for $\mathrm{Hp}+\mathrm{ve}$ males were $£ 37$ overall, for males with GORD $£ 67$, without GORD £27; for Hp +ve females £33 overall, with GORD £33, without GORD £33. Costs for $\mathrm{Hp}$-ve males were $£ 16$ overall, with GORD $£ 21$, without GORD $£ 14$; for $\mathrm{Hp}-\mathrm{ve}$ females $£ 22$ overall, with GORD $£ 38$, without GORD £8.

Conclusion Helicobacter pylori eradication can be financially worthwhile in patients with Non Ulcer Dyspepsia but perhaps not in females with evidence of gastro-oesophageal reflux disease.

\section{A:12 DELAYED GASTRIC EMPTYING UNCHANGED AFTER CURE OF H. PYLORI INFECTION IN FUNCTIONIAL DYSPEPSIA}

U. Peitz, S. Blaudszun, B. Tillenburg, S. Aygen ', O. Hennemann ', M. Stolte ${ }^{2}$, G. Börsch, J. Labenz. Elisabeth Hospital, Essen, Germany; ${ }^{1}$ INFAI, Bochum, Germany; ${ }^{2}$ Institute of Pathology, Bayreuth, Germany

Purpose: There seems to be a smaller subgroup of $H$. pylori (HP) infected functional dyspepsia (FD) patients profitting of HP cure. The influence of HP cure on FD symptoms and gastric emptying is investigated in this study.

Methods: 18 patients with FD have been enrolled. HP infection was assessed pretherapeutically by consisting results of culture and histology from gastric biopsies. The infection was cured in all patients by a one-week triple therapy comprising omeprazole, clarithromycin and amoxicillin as determined 4 weeks and 6 months posttherapeutically by urea breath test. Gastric emptying was measured by a previously validated ${ }^{13} \mathrm{C}$-octanoic acid breath test pre- as well as 4-8 weeks and 6-7 months posttherapeutically.

Results: 4-8 weeks (resp. 6-7 months) after HP cure, there was a major symptom relief stated by $9(6)$ patients, a slight relief in $5(8)$, no change in 3 (3) and worsening of symptoms in 1 (1) cases. Gastric half-emptying time $(\mathrm{t} 1 / 2, \mathrm{~min})$ data are given in the following table:

\begin{tabular}{llll}
\hline Parameter: $\mathrm{t} 1 / 2$ & Pre 4-8 weeks & $6-7$ months & \\
\hline Mean: & 117.6 & 108.8 & 117.6 \\
Median: & 115 & 114 & 120 \\
SD & 35.1 & 33.3 & 33.3 \\
Minimum & 64 & 56 & 72 \\
Maximum & 181 & 163 & 200 \\
\hline
\end{tabular}

The differences were not significant in Wilcoxon test $(p=0.42$ after 4-8 weeks, $p=0.97$ after 6-7 months).

Conclusions: Gastric emptying was delayed in FD patients with a wide interindividual variation. HP cure did not change consistently the $t 1 / 2$ in the short or long term. Also, change of $t 1 / 2$ was not closely related to symptom relief.

\section{A:13 PRIMARY AND SECONDARY METRONIDAZOLE RESISTANT HELICOBACTER PYLORI IN AN URBAN ASIAN POPULATION}

E.K. Teo, K.M. Fock, T.M. Ng, S.C. Chia, C.J.L. Khor, A.L. Tan '

C.C. Tan. Div of Gastroenterology, Dept of Medicine, Singapore; ${ }^{1}$ Dept of Microbiology, Toa Payoh Hospital, Singapore

The prevalence of metronidazole resistance in $\mathrm{H}$. Pylori varies from $5 \%$ to $90 \%$ in different countries. Eradication of H. Pylori using nitroimidazole derivative is adversely affected by metronidazole resistance. We aim to assess the prevalence of in-vitro metronidazole resistant H. Pylori over two and a half years and to determine the factors affecting Metronidazole resistance. 
Between September 1993 to March 1996, four hundred and two isolates were obtained from three hundred and eighty-one patients. (277 males: 104 females mean age: 50 years old. $85 \%$ with peptic ulcer disease). Antral biopsies were obtained and cultured in typticase soy agar at $35^{\circ} \mathrm{C}$ under microaerophillic condition for eight days. Antibiotic susceptibility was tested by disk diffusion technique. Metronidazole resistance was defined as the presence of colonies within fifteen millimetre margin from the disk The patients' medical and prescription records were screened for prior use of metronidazole.

The mean resistant rate was $60.7 \%$. Primary resistance constitute $88 \%$ while secondary resistance was documented in $2.6 \%$ of the patients with resistant strains isolated. The resistant rate was $45.2 \%$ in the first twelve months, $69.7 \%$ in the second and $81.7 \%$ in the last six months. (p < $0.0001)$. The resistant rate was higher in females $(69.1 \%)$ than in males $(57.5 \%)(p=0.045)$. There was no difference in resistant rates between different races, age group, smoking, ethanol or NSAIDs consumption.

In conclusion, there is a significant rise in metronidazole resistance over two and a half years. Primary resistance contributes to the majority of metronidazole resistance. Acquired resistance was encountered in six out of eight patients who failed triple therapy. A high proportion of patients (75\%) developed secondary resistance to metronidazole after failure of triple therapy.

\section{A:14 HELICOBACTER PYLORI AND GASTRIC EMPTYING IN PATIENTS WITH NON-ULCER DYSPEPSIA}

K.M. Fock, K.S. Chia, Y.Y. Chong. Div of Gastroenterology, Dept of Medicine, Toa Payoh Hospital, and National University Hospital, Singapore

Delayed gastric emptying has been shown to be present in $50 \%$ to $60 \%$ of patients with functional dyspepsia but the role of $\mathrm{H}$. Pylori in non-ulcer dyspepsia is controversial. The aim of this study was to assess the role of $\mathrm{H}$. Pylori, gastric emptying (using radio-opaque marker) in patients with non-ulcer dyspepsia.

Thirty-three healthy volunteers (C) who had no symptoms, normal upper GI endoscopy and abdominal ultrasonography were recruited together with 72 consecutive patients $(P)$ with non-ulcer dyspepsia. Gastric emptying was assessed using ten radio-opaque markers which were given to subjects and patients with a standard meal after an overnight fast and serial abdominal $\mathrm{X}$-rays were performed until all the ROMs have left the stomach. The time taken for all 10 radio-opaque markers to clear the stomach was determined in each group. Delayed gastric emptying was seen in $14 \%$ of patients and none in the control group. Endoscopy was performed and antral biopsies were taken for histological examination for $\mathrm{H}$. Pylori. The two groups were comparable in mean age (control 33.3 years vs patients 31.2 years). $\mathbf{H}$ Pylori was present in $28 \%$ of controls and $31 \%$ of patients.

A multiple linear regression model was used to determine the relationship between gastroparesis, H. Pylori status and symptoms of non-ulcer dyspepsia. The odds ratio of a patient with delayed gastric emptying (paresis) and having symptoms of non-ulcer dyspepsia was 2.5 (CI 2-13) which was statistically significant. The odds ratio of persons with $\mathrm{H}$. pylor infection and symptoms of non-ulcer dyspepsia was 1.3 (CI 0.5-3.7). With both $\mathrm{H}$. Pylori infection and paresis present the odds ratio was 4.1 ( $\mathrm{CI}$ 2.4-40.4)

We conclude that delayed gastric emptying is related to non-ulcer dyspepsia symptoms. H. Pylori infection, per se, does not appear to be related to non-ulcer dyspepsia. There is interaction between gastric paresis and $\mathrm{H}$. Pylori infection with symptoms of non-ulcer dyspepsia.

\section{A:15 SHORT TERM TREATMENT WITH RANITIDINE BISMUTH CITRATE (RBC) IMPROVES H. PYLORI GASTRITIS IN THE ANTRUM AND CORPUS}

D.Y. Graham, J.H. Walsh, T.T. Schubert, F.L. Lanza, D.A. Peura, W. Peterson, D.S. Riff, J. Yardley, A.A. Ciociola, S. Kong, D.D. Webb. VA Med Houston TX USA; CURE LA CA; Dig Consul, Tacoma WA; Clin Res Houston TX; UVA, Charlottesville VA; VA Med Dallas TX; Gastro Group, Anaheim CA; Johns Hopkins Balt. MD; Glaxo RTP, NC, USA

Introduction: We previously reported data from this study on the effect of RBC on antral gastritis. Some studies have shown short term omeprazole therapy in $H$. pylori (Hp) positive patients causes significant (sig) proximal migration of $\mathrm{Hp}$ gastritis activity from antrum to corpus. We now report additional data on the effect of RBC on corpus gastritis. Purpose: This randomized, double-blind study investigated the effects of short term RBC therapy on Hp gastritis patterns in the antrum and corpus. Methods: 125 subjects with $\mathrm{Hp}$ infection ( ${ }^{13} \mathrm{UBT}$ ) were treated for 12 wks with either Placebo (PLA), RBC400 mg or RBC800 mg bid. Two biopsies each were taken from the antrum, corpus greater curve (CGC) and lesser curve (LC) at the Wk 0, 6, 12 visits. All biopsies were evaluated by a single pathologist (blinded) for polymorphonuclear (PMN), monocytes, $H p$ density, atrophy, and metaplasia. Each was graded as none (0), minimal (1), mild (2), moderate (3), or severe (4). Results: RBC800 sig reduced antral and LC PMN infiltration. Hp density was sig reduced in antrum, LC and CGC. No changes in monocytes, atrophy or metaplasia were observed. Similar changes were seen with RBC400. Only RBC800 data are shown below.

Patients With Mild to Severe PMN Infiltration (\%)

\begin{tabular}{|c|c|c|c|c|c|c|}
\hline \multirow[t]{2}{*}{ Wk. } & \multicolumn{2}{|c|}{ Antrum } & \multicolumn{2}{|c|}{ Corpus LC } & \multicolumn{2}{|c|}{ Corpus GC } \\
\hline & PLA & RBC & $\overline{\text { PLA }}$ & RBC & PLA & RBC \\
\hline $\begin{array}{l}0 \\
6 \\
12\end{array}$ & $\begin{array}{l}43 \% \\
49 \% \\
51 \%\end{array}$ & $\begin{array}{l}35 \% \\
10 \% * \\
18 \%^{*}\end{array}$ & $\begin{array}{r}8 \% \\
20 \% \\
24 \%\end{array}$ & $\begin{array}{l}14 \% \\
11 \% \\
17 \%\end{array}$ & $\begin{array}{l}22 \% \\
14 \% \\
26 \%\end{array}$ & $\begin{array}{l}29 \% \\
19 \% \\
18 \%\end{array}$ \\
\hline
\end{tabular}

$* \mathrm{p}<0.05$ vs. PLA

Conclusions: RBC improves Hp gastritis (PMN) and reduces Hp density. Short term treatment with RBC does not induce corpus migration of $\mathrm{Hp}$ associated gastritis.

\section{A:16 EFFECTS OF LONG-TERM ACID SUPPRESSION ON $H$. PYLORI GASTRITIS}

R. Fiocca ${ }^{1}$, G. Dobrilla ${ }^{2}$ for the Italian Duodenal Ulcer Group for the Study of Lansoprazole. ${ }^{1}$ University of Pavia, Italy; ${ }^{2}$ Bolzano Regional Hospital, Italy

Aim: to study the effects of long-term treatment with proton pump inhibitors (PPI) on chronic gastritis and their reversibility.

Methods: 251 duodenal ulcer (DU) patients were enrolled in a randomized, double blind, polycentric study. They had either lansoprazole $30 \mathrm{mg}$ or omeprazole $40 \mathrm{mg}$ for 28 days and afterwards were treated long-term (12 months) with lansoprazole $15 \mathrm{mg}$ (group A) or $30 \mathrm{mg}$ (group B) or omeprazole $20 \mathrm{mg}$ (group C). Endoscopy took place at entry, 28 days, 6 and 12 months, as well as 6 months after therapy discontinuation. Histological evaluation (Sydney system criteria) was centralized. Wilcoxon matched-pairs signed-ranks test was used.

Results: in the healing phase (entry vs 28 days) a highly significant improvement occurred (for all treatment groups) in antral inflammation $(p=0.0000)$, activity $(p=0.0000)$ and $H$. pylori (HP) colonization ( $p=$ $0.0000)$, coupled with worsening in corpus inflammation $(\mathrm{p}=0.0000)$ and activity $(\mathrm{p}=0.0000)$. In the maintenance phase ( 28 days vs 12 months) group $\mathrm{A}$ and $\mathrm{C}$ patients, who had lower PPI intake than in the healing phase, showed a significant worsening in antral activity $(p=0.0001$ for group $A$ and 0.0014 group $C$ ) and HP colonization ( $p=0.0000$ group $A$ - and 0.0068 group $C$ ) and an improvement in corpus activity ( $p=$ 0.0022 group $\mathrm{A}$ - and 0.0124 group $\mathrm{C}$ ). On the contrary, no significant variation was seen in group B patients (with unchanged PPI dosage during healing and maintenance phase), apart from further improvement in antral inflammation $(p=0.0455)$. Sixtysix patients were re-examined 6 months after treatment discontinuation (follow-up phase, 12 vs 18 months). They showed a highly significant worsening in antral inflammation $(p=0.0058)$ activity $(p=0.0180)$ and HP colonization $(p=0.0000)$ coupled with improvement of corpus inflammation $(p=0.0000)$, activity $(p=0.0000)$ and HP colonization ( $p=0.0006$ ), for all treatment groups. No significant change in the severity of atrophy and intestinal metaplasia was found.

Conclusions: PPI treatment has an early, positive effect on antral gastritis and HP infection and a negative one on corpus gastritis. These effects persist when treatment is maintained long-term and are dose-dependent. Treatment suspension seems to restore the initial conditions.

\section{A:17 H. PYLORI AND GASTRIC METAPLASIA IN DUODENAL BULB (DGM) ARE NOT RELATED PARAMETERS IN NON-DUODENAL ULCER PATIENTS}

D. Pospai, C. Vissuzaine, S. Forestier, M. Mignon. Bichat-Claude Bernard Hospital, Paris, France

In duodenal ulcer (DU), gastric metaplasia in the proximal duodenum (DGM) and Hp gastritis are the most prevalent histological findings, suggesting a cause-effect relationship for ulcer development. In order to verify whether such high association is restricted to DU or observed also in non-DU pts, hundred and eight cases with normal upper endoscopy, were prospectively investigated in the present study: 37 asymptomatic controls without history of peptic disease and 71 non-ulcer dyspepsia (NUD) Methods: 1-2 biopsies from each of the four walls (w) [anterior (aw) posterior (pw), superior (sw) and inferior (iw)] mean 6, range 4-8, were taken from the mid duodenal bulb and stained with PAS (DGM). DGM prevalence and extent (as \% of the total epithelial surface measured in biopsies) assessment, was carried out by two independent histopathologists. Hp pattern was determined by histology (6 Sydney System biopsies), CLO test, and immunohistochemistry. 
Results:

\begin{tabular}{llllll}
\hline & \multicolumn{2}{l}{$\mathrm{Hp}+\mathrm{ve}(\mathrm{n}=61)$} & & \multicolumn{2}{c}{$\mathrm{Hp}-\mathrm{ve}(\mathrm{n}=47)$} \\
\cline { 2 - 3 } \cline { 6 - 7 } & DGM +ve & DGM -ve & & DGM +ve & DGM -ve \\
\hline Controls & 1 & 15 & 7 & 14 \\
NUD & 11 & 34 & 7 & 19 \\
Total $n(\%)$ & $12(20)$ & $49(80)$ & $14(30)$ & $33(70)$ \\
\hline
\end{tabular}

No significant difference was found in prevalence of DGM in HP +ve vs Hp - ve cases $(p=0.22), 12 / 61$ vs $14 / 47$ respectively. The extent of DGM was not different in HP -ve controls, Hp - ve NUD and Hp + NUD pts: mean (range) \%; $25(10-60), 20(5-50)$ and $10(5-30)$ respectively.

The location of DGM was restricted in a single quadrant in $85 \%$ of cases. There was no significant difference concerning the location between DGM +ve Hp +ve cases (6 sw, 4 aw, 1 iw and 1 pw) and DGM +ve Hp -ve cases (6 sw, 5 aw, 1 iw and 2 pw).

Conclusion: No relation was found between prevalence, extent and location of DGM and Hp pattern in non-DU patients.

\section{A:18 H.p. ERADICATION IN NON ULCER DYSPEPSIA (NUD): A PROSPECTIVE RANDOMIZED SIX MONTHS STUDY}

M. Bortolon, N. Dal Bò, S. Salandin, A. Buda, S. Kusstatscher, G. Laino, G. Leandro ${ }^{1}$, G. Battaglia ${ }^{2}$, F. Vianello, M. Cassaro, M. Rugge, F. Di Mario. Padua, Italy; ${ }^{1}$ Castellana Grotte (BA), Italy; ${ }^{2}$ Venice, Italy

The usefulness of H.p. eradication in NUD is still controversial. For a better evaluation of dyspeptic patients which could have an improvement of their symptoms after eradication, they were subdivided in three groups: A: ulcer-like; B: dismotility-like; C: reflux-like. Methods: 119 H.p. positive subjects (61 M; mean age 51.5; range 25-76) entered an open, prospective controlled study. All underwent different treatment schedules with either Amoxicillin or Clarithromycin plus Metronidazole and Omeprazole for one week. Endoscopy: at baseline and two months after the end of therapy (T2); 7 gastric biopsies were taken from gastric antrum and body to assess $\mathrm{Hp}$ status by histology (Giemsa, Warthin Starry, immunohistochemistry) and rapid urease test (CLO test). All pts remained untreated for a six months follow-up period (T6). Results: Overall, 86/119 (74.5\%) pts were cured and $96 \%$ showed a disappearance of gastritis activity at T2. Eradication rate in the 3 groups was $79.3 \%$ group A; $68.3 \%$ group $B ; 75.8 \%$ group C). Overall, $45 \%$ of eradicated subjects and $22 \%$ of not-eradicated were asymptomatic at T2, $31 \%$ and $6.2 \%$ at T6, respectively. Subdividing the pts according with their symptomatological pattern, the percentages were as follows: Group A: T2 $=60.9 \%$; $\mathrm{T} 6=65.2 \%$ Group B: $\mathrm{T} 2=36.5 \%$ T6 $=7.4 \%$ Group C T2 $=43.5 \%$; T6 $=39.2 \%(p=0.001)$. Conclusions: 1) Overall, $44.8 \%$ and $31 \%$ of dyspeptic pts were symptom-free 2 and 6 months after a successful H.p eradication therapy, respectively. 2) Higher asymptomatic rate was obtained in the ulcer-like group (60.9\% at $\mathrm{T} 2$ unchanged at T6); 3) The disappearance of gastritis activity was confirmed in $96 \%$ of cured patients.

\section{A:19 THE RELATIONSHIP BETWEEN H. PYLORI GASTRITIS AND GERD}

A. Hackelsberger, V. Schultze, T. Günther ${ }^{1}$, P. Malfertheiner. Dept. of Gastroenterology, University of Magdeburg, Ger.; ' Dept. of Pathology, University of Magdeburg, Ger.

Background: Few data on the relation between chronic H. pylori (HP)gastritis and gastroesophageal reflux (GERD) exist.

Aim: To compare the histologic pattern of gastritis in the cardia from patients with erosive GERD to that of patients with chronic gastritis.

Patients and Methods: Two endoscopic biopsies of antrum, body and cardia mucosa (within $1 \mathrm{~cm}$ below the squamocolumnar junction) were obtained in 450 consecutive patients. Gastritis (modified Giemsa, HE, AB-PAS) was graded by the Sydney System on a four pt scale ( 0 to 3$)$ for activity, degree, HP colonization (HP-C), atrophy and intestinal metaplasia (IM). The HP-status was assessed by histology and rapid urease test. If necessary an additional Warthin Starry stain and in some pats 13-CUBT, culture, and serology were performed. At endoscopy 61 pats showed erosive lesions in the esophagus, forming the GERD group. As controls 212

\begin{tabular}{llllll}
\hline & Activity & Degree & HP-C & Atrophy & IM \\
\hline HP +ve GERD & & & & & \\
Antrum & 1.423 & 2.038 & 1.192 & 0.115 & 0.231 \\
Corpus & 1.308 & 1.538 & 1.192 & 0 & 0.038 \\
$\quad$ Cardia & 0.846 & 1.538 & 0.538 & 0.077 & 0.154 \\
HP +ve Gastritis & & & & & \\
Antrum & 1.413 & 1.952 & 1.427 & 0.221 & 0.240 \\
Corpus & 1.181 & 1.733 & 1.324 & 0.202 & 0.114 \\
Cardia & $1.135^{*}$ & 1.731 & $0.99 * *$ & 0.058 & 0.173 \\
& p $<0.05$ & & p $<0.01$ & & \\
\hline
\end{tabular}

pats with gastritis, without ulcers, erosive lesions and GERD symptoms were selected.

Results: 26 out of 61 GERD pats were HP +ve (42\%), 35 were HP -ve (58\%). Of 212 pats with gastritis 104 were HP +ve (49.1\%), 108 were HP -ve (50.9\%). Age and sex in these groups were equally distributed. No differences were found between GERD and gastritis in HP -ve pats.

Conclusion: A causal link between chronic HP + ve gastritis and GERD is unlikely. Reflux may however create a more hostile environment for HP, as the activity of gastritis and density of HP-C in the cardia region are significantly decreased in pats. with GERD.

\section{A:20 ECONOMIC MODELING OF TREATMENT REGIMENS FOR $\boldsymbol{H}$. PYLORI RELATED BLEEDING DUODENAL ULCER}

N. Vakil. University of Wisconsin, Milwaukee, WI, USA

Bleeding ulcers are an important cause for hospital admissions and account for a substantial portion of the costs of ulcer disease treatment We computed a decision analysis model to examine the clinical \& economic outcomes of treatment regimens for bleeding DU over a 1 year period. Methods: The decision analysis model includes costs of endoscopic hemostasis and surgery. The regimens studied were: $\mathrm{H} 2$ receptor antagonist (H2RA) for 8 weeks followed by observation, H2RA for 8 weeks followed by maintenance therapy for 1 year. Treatments directed at $H$. Pylori were 3 recently described short-term, triple-drug regimens from the MACH 1 trial: a) MOC-R regimen: Omeprazole 20 + Clarithromycin + Metronidazole for 1 week followed by ranitidine $300 \mathrm{mg}$ for 4 weeks. Eradication rate $92 \%$. b) MOC-O regimen: Omeprazole 20 + Clarithromycin + Metronidazole for 1 week followed by omeprazole $20 \mathrm{mg}$ for 3 weeks. Eradication rate $92 \%$. c) MO40C-R regimen Omeprazole 40 + metronidazole + clarithromycin for 1 week followed by ranitidine $300 \mathrm{mg}$ daily for 4 weeks. Eradication rate $88 \%$. Costs were calculated over the 1 year period using published recurrence rates. Sensitivity analysis was performed to test the assumptions in the model. Results: Overall costs per patient treated: 8 week $\mathrm{H} 2$ RA: \$3194, acute H2RA followed by maintenance: \$1563, MO40C-R regimen: \$655, MOC-R regimen: \$406, MOC-O regimen: \$402, Bismuth triple therapy: $\$ 308$. Sensitivity analysis demonstrated that bismuth based triple drug therapy was the least expensive regimen as long as eradication rates exceeded $86 \%$. When eradication rates fell below $86 \%$, the MOC-R regimen became the least expensive. Conclusions: One week proton pump inhibitor based triple therapies are cost-effective strategies. Bismuth based triple therapies are the least expensive strategy where resistance in the population is low and compliance is likely to be high. In areas where high resistance rates make the overall eradication rates with bismuth based triple therapy lower than $86 \%$, or in areas where metronidazole resistance rates are unknown, proton pump inhibitor based triple therapies should be preferred. Eradication rates are the principal determinant of both the efficacy and the cost of any therapeutic strategy.

\section{A:21 H. PYLORI ERADICATION AND PEPTIC ULCER RECURRENCE. COMPARISON OF ERADICATION THERAPY AND MAINTENANCE TREATMENT}

H. Lamouliatte ${ }^{1}$, Ch. Florent ${ }^{2}$, F. Vicari ${ }^{3}$, F. Mégraud ${ }^{4}$, S. Forestier ${ }^{5}$ ${ }^{1}$ Hôpital Saint-André Bordeaux; ${ }^{2}$ Hôpital Saint-Antoine Paris; ${ }^{3}$ Nancy; ${ }^{4}$ Hôpital Pellegrin Bordeaux; ${ }^{5}$ Puteaux

Few studies have compared the relapse rate in patients with duodenal ulcer (DU) with either triple therapy for $H$. pylori eradication or maintenance treatment with an antisecretory drug alone.

The aim of this double blind, randomized (ratio: $2 / 1$ ) study was to assess the eradication rate of triple therapy, lansoprazole (L) plus amoxicillin (A) plus metronidazole (M) and to compare the relapse rates of ulcer on a 12-month period in LAM gr with maintenance therapy with ranitidine (R). We performed an interim analysis on available data at 6 months follow up.

Subjects and Methods: Patients received for 4 weeks $30 \mathrm{mg} / \mathrm{d}$ of $\mathrm{L}$ associated for 10 days either with $\mathrm{A}(1 \mathrm{~g}$ bid) and $\mathrm{M}$ (500 mg tid) (LAM gr) or 2 antibiotic placebos (LR gr); then for 12 months: ranitidine placebo (LAM gr) or ranitidine $150 \mathrm{mg} / \mathrm{d}$ (LR gr). Subjects were considered $H$. pylori positive if rapid urease test and one of the following centralized tests (histology and/or culture and/or PCR) were positive. Metronidazole resistance was defined as $\mathrm{MIC}_{90}>8 \mathrm{mcg} / \mathrm{ml}$. Eradication was proved if both centralized tests were negative. Recurrence was assessed by endoscopy performed in symptomatic patient at control visit (M3 or M6).

Results: 229 patients were evaluable for eradication of $H$. pylori (LAM $\mathrm{gr}=160, \mathrm{LR} \mathrm{gr}=69)$. Eradication rates were in per protocol $79 \%[95 \% \mathrm{Cl}$ $=72.2-86 \%$ ] in LAM gr and $8 \%$ [95\% CI $=1.3-14.8 \%$ ] in LR gr [intent in . . . $72 \%$ (95\% CI $=62.2-76.5 \%)$ versus $7 \%(95 \% \mathrm{CI}=1.1-13.5 \%)$ ]; in LAM gr $52 \%$ of strains were metronidazole resistant. 158 patients were evaluable at 6 months for ulcer relapse (LAM gr $=112, \mathrm{LR}$ gr $=46)$. DU rela ... : ates were $3.5 \%(95 \% \mathrm{CI}=0-13.7 \%)$ in LAM gr and $4.5 \%(95 \%$ 
$\mathrm{CI}=0-10.24 \%$ ) in LR gr (NS). 3 out of 4 patients who relapsed in LAM gr were not eradicated.

Conclusion:

1. Triple therapy L ( $30 \mathrm{mg} / \mathrm{d})$ plus 2 antibiotics is effective in $H$. pylori gastric infection with eradication rate of $79 \%$.

2. Eradication therapy prevents duodenal ulcer relapse as the maintenance therapy.

\section{A:22 H. PYLORI INFECTION INCREASES THE RISK OF PEPTIC ULCER BLEEDING - A CASE-CONTROL STUDY}

H. Köhl, F. Leverkus, J. Labenz. Elisabeth Hospital Essen, Germany

Aim: The study was designed to evaluate the role of $H$. pylori infection in the pathogenesis of peptic ulcer bleeding.

Methods: 128 patients presenting with upper GI bleeding and 128 matched controls (age and gender) were studied prospectively. In all patients and controls a standardized questionnaire was performed. Patients were investigated endoscopically with assessment of $H$. pylori infection by a rapid urease test, culture and histology. In controls, the current H. pylori status was determined using a 13C-urea breath test. Statistics included the Cochran-Mantel-Haenszel test and a conditional multiple logistic regression analysis (CMLR).

Results: 72 patients had peptic ulcer bleeding (gastric ulcer (GU): n $=39$; duodenal ulcer (DU): $n=33$ ) and 56 patients bled from other sources. $H$. pylori infection was more frequently detected in ulcer patients than in controls (GU: OR 4.3 95\%-CI 1.6-11.5, $\mathrm{p}=0.005$; DU: OR 3.3 $95 \%$-CI 1.1-9.4, p < 0.03), while the infection was not related to non-ulcer bleeding (OR $1.295 \%$-CI $0.6-2.5, \mathrm{p}=0.59$ ). NSAID use was associated with an increased risk of gastric ulcer bleeding (OR 4.5 95\%-CI 1.1-18.2, $\mathrm{p}=0.035$ ). CMLR suggested that $\boldsymbol{H}$. pylori infection is an independent risk factor for peptic ulcer bleeding (OR $3.395 \%-C I 1.5-7.0$ ), $p=0.002$ ). No interactions could be detected between the infection and NSAID use.

Conclusions: $H$. pylori infection increases independently the risk of peptic ulcer bleeding. Thus, cure of the infection will lead to a decreased incidence of ulcer bleeding. However, it cannot be expected that curing $H$. pylori infection in NSAID users will substantially diminish the risk of ulcer complications.

\section{A:23 QUALITY ASSESSMENT OF TRIPLE THERAPY FOR DUODENAL AND GASTRIC ULCER IN EVERYDAY CLINICAL LIFE}

E.K. Philipsen, C.P. Hansen, O.Ø. Thomsen. Herlev Hospital, University of Copenhagen, Denmark

Aim: To assess the efficacy of triple therapy in everyday clinical life in patients with duodenal ulcer (DU) or gastric ulcer (GU).

Methods: Eightyone patients (43 males) (age 63 years, median; 24-87 years, range) with DU (55) or GU (26) with no intake of NSAID were all consecutively prescribed oral treatment with amoxicillin $2000 \mathrm{mg}$, metronidazole $1500 \mathrm{mg}$, daily for 2 weeks, and omeprazole $40 \mathrm{mg}$ daily for 2 weeks (DU) and 4 weeks (GU). Gastroscopy was performed at inclusion and at 2 weeks (DU) and 4 weeks (GU) after start of treatment. The treatment with omeprazole was continued if the ulcer was unhealed until another endoscopy was performed after 4-6 weeks. Antrum biopsies were examined for $\mathrm{H}$. pylori (histology, culture and urea-test). Control visits were performed at 3 and 12 months after the initial gastroscopy.

Results: In the DU group 5 and 9 patients, and in the GU group 6 and 8 patients died during the study period (all from non-ulcer diseases), or were lost to follow at 3 and 12 months, respectively. The number of patients with presence or absence of dyspepsia in the one year follow-up period is given below:

\begin{tabular}{llllll}
\hline & \multicolumn{2}{l}{ Duodenal ulcer } & & Gastric ulcer \\
\cline { 2 - 3 } \cline { 5 - 6 } Symptoms & 3 months & 12 months & & 3 months & 12 months \\
\hline No & $47 / 50$ & $42 / 46$ & $18 / 20$ & $16 / 18$ \\
& $(94 \%)$ & $(91.3 \%)$ & & $(90 \%)$ & $(88.9 \%)$ \\
Yes & $3 / 50$ & $4 / 46$ & $2 / 20$ & $2 / 18$ \\
& $(6 \%)$ & $(8.7 \%)$ & $(10 \%)$ & $(11.1 \%)$ \\
\hline
\end{tabular}

Conclusion: The effect of triple therapy (amoxicillin, metronidazole and omeprazole) in daily clinical routine, is similar to that published in clinical controlled studies.
3A:24 PREVENTION OF NSAID-INDUCED ULCER BY ERADICATION OF H. PYLORI. A PROSPECTIVE RANDOMIZED STUDY

Y.T. Lee ${ }^{1}$, F.K.L. Chan ${ }^{1}$, J.Y. Sung ', V.K.S. Leung ${ }^{1}$, K.F. To ${ }^{2}$, M.Y. Yung ${ }^{3}$, E. Hui ${ }^{1}$, C.S.Y. Chan ${ }^{4}$, S.C.S. Chung ${ }^{3}$, J. Woo ${ }^{1} .{ }^{1}$ Dept of Medicine, ${ }^{2}$ Dept. of Pathology, ${ }^{3}$ Dept. of Surgery, ${ }^{4}$ Dept. of Community Medicine, The Chinese University of Hong Kong, Hong Kong

The role of $H$. pylori infection in NSAID-related ulcer disease is unclear Whether eradication of $H$. pylori can reduce the risk of NSAID-induced ulcer has not been studied before.

Aim: To study if eradication of $H$. pylori infection prior to NSAID therapy could prevent ulcer development.

Method: Patients with musculoskeletal pain were offered gastroscopy prior to NSAID treatment to document $H$. pylori infection and absence of ulcer. Those with a history of ulcer or usage of NSAID in last 2 months were excluded. Eligible patients were randomized to receive either naprosyn (750 mg daily) alone or one-week of triple therapy (bismuth, tetracycline and metronidazole) prior to naprosyn. Endoscopy were repeated at 8 weeks or earlier if ulcer complications occurred.

Results:

\begin{tabular}{llll}
\hline & Naprosyn alone & Triple + Naprosyn & P \\
\hline No. of patients & 20 & 22 & \\
M:F & $1: 2.5$ & $1: 1.6$ & \\
Median (range) age & $58(40-84)$ & $64(41-78)$ & \\
HP eradication (\%) & $0(0)$ & $20(91)$ & $<0.001$ \\
Total No. of Ulcer (\%) & $5(25)$ & $1 *(4.5)$ & 0.07 \\
GU/DU & $3 / 2$ & $1 / 0$ & \\
Ulcer pain (\%) & $3(15)$ & $1(4.5)$ & 0.27 \\
Ulcer bleeding (\%) & $1(5)$ & $0(0)$ & 0.48 \\
\hline
\end{tabular}

(*failed $H$. pylori eradication)

$5 / 20$ patients $(25 \%)$ in naprosyn group vs $0 / 20$ patients with successful $H$. pylori eradication developed ulcer $(\mathrm{P}<0.05)$.

Conclusion: Eradication of $H$. pylori prior to NSAID therapy reduces the occurrence of peptic ulcer.

\section{A:25 HELICOBACTER PYLORI AND NSAIDS IN BLEEDING GASTRIC ULCER}

T.M. Ng, K.M. Fock, J.L. Khor, E.K. Teo, S.C. Chia. Division of Gastroenterology, Department of Medicine, Toa Payoh Hospital, Singapore

Helicobacter pylori $(\mathrm{Hp})$ infection and Nsaids are independent risk factors for gastric ulcer (GU) and their effect may be additive. However the question as to whether they interact to influence the risk of bleeding in GU has little been studied.

We aim to determine the prevalence of $\mathrm{Hp}$ infection and Nsaids ingestion in a group of patients with GUs only and explore their roles in bleeding and nonbleeding GUs.

From January 1993 to June 1995, a total of 145 GU patients (103 M:42 F, median age 61, range 26-94) were recruited into the study. One hundred and twenty GU patients $(83 \%)$ were $\mathrm{Hp}$ positive and $25(17 \%)$ were $\mathrm{Hp}$ negative. Nsaids ingestion within 4 weeks prior to endoscopy were present in $30 \%$, more in Hp negative than Hp positive patients $(56 \%$ vs $24 \%$ ) (p = 0.003 ). Aspirin accounted for $37 \%$ of the Nsaids consumed. Seventy-one patients have bleeding GU (49 M:22 F, median age 69, range 26-94) and 74 with nonbleeding GU (54 M:20 F, median age 58, range 29-86). Logistic regression analysis (SAS) was used to evaluate the effect of $\mathrm{Hp}$ infection, Nsaids ingestion, age, gender, smoking, alcohol consumption and past PUD on bleeding GU. Nsaids ingestion was the only significant risk factor found ( $\mathrm{p}<0001)$. The risk of bleeding was $63.7 \%(95 \% \mathrm{CI}=55.9 \%-71.6 \%)$ if Nsaids alone was present. The probability of bleeding with $\mathrm{Hp}$ alone was $44 \%(95 \% \mathrm{CI}=35.9 \%-52.1 \%)$. When both $\mathrm{Hp}$ and Nsaid were present the risk of bleeding was $71.8 \%(95 \% \mathrm{CI}=64.6 \%-79.1 \%)$. The interaction of $\mathrm{Hp}$ and Nsaid use was statistically significant $(\mathrm{p}=0.025)$.

In conclusion, the prevalence of $\mathrm{Hp}$ infection and Nsaids ingestion in GU patients was $83 \%$ and $30 \%$ respectively. Nsaids ingestion increases the risk of bleeding in $\mathrm{GU}$ patients whereas $\mathrm{Hp}$ alone is not a risk factor. There may be some synergisms between $\mathrm{Hp}$ and Nsaids in increasing the risk of bleeding.

\section{A:26 Helicobacter pylorl, GASTRIC ULCER AND NON-STEROIDAL} ANTI-INFLAMMATORY DRUGS

D. Boixeda, J.P. Gisbert, F. Bermejo, I. Alvarez Baleriola, R. Cantón, R. Aller, C. Martín de Argila. "Ramón y Cajal" Hospital, Madrid, Spain

Purpose: To describe the prevalence of $H$. pylori infection in gastric ulcer (GU) patients and to study its relationship with non-steroidal antiinflammatory drug (NSAID) administration. 
Methods: 161 patients with active GU were studied (mean age: 54 years, $70 \%$ males). In all patients 3 biopsy specimens were taken from both gastric antrum and body (H\&E stain, Gram stain and culture).

Results: $H$. pylori was found in $83 \%(95 \% \mathrm{CI}=77-89 \%)$ of patients. In non-NSAID users $H$. pylori infection reached $87 \%(95 \% \mathrm{CI}=81-93 \%)$, while in NSAID users the corresponding figure was $63 \%(\mathrm{CI}=43-79 \%)$ $(p=0.008)$. The percentage of $\mathrm{GU}$ patients without $H$. pylori infection not taking NSAIDs was $11 \%(\mathrm{CI}=6-16 \%)$. In multiple logistic regression analysis NSAID administration was the only variable which correlated with $H$. pylori infection (odds ratio $=0.25 ; 95 \% \mathrm{CI}=0.09-0.66 ; \mathrm{chi}^{2}$ model $=7.27 ; \mathrm{p}=0.007$ ). Additional variables (age, sex, smoking, alcohol, and GU location) were not correlated with $H$. pylori infection. Chronic gastritis percentages were higher in $H$. pylorit than in $H$. pylori- patients $(97 \%$ vs $67 \%$ at antrum, and $78 \%$ vs $42 \%$ at body) (p $<0.001$ )

Conclusion: The overall prevalence of $H$. pylori infection in GU patients was $83 \%$; this prevalence increased up to $87 \%$ when only non-NSAID users were considered. The percentage of GU patients without $H$. pylori infection not taking NSAIDs was only $11 \%$, which suggests that both factors ( $H$. pylori and NSAIDs) are the most relevant in GU disease, the emergence of GU without them being uncommon.

\section{A:27 ON WHICH FACTORS DOES DUODENAL ULCER HEALING DEPEND WHEN A H. PYLORI ERADICATION THERAPY IS USED?}

J.P. Gisbert, D. Boixeda, L. De Rafael, C. Martín de Argila, M. García, R. Aller, A. García Plaza. "Ramón y Cajal" Hospital, Madrid, Spain

Purpose: To study the influence of various factors on duodenal ulcer healing, specially therapy success or therapy failure on $H$. pylori eradication, and to verify whether the administration of an proton pump inhibitor for the antibiotic administration period (one or two weeks) is enough to obtain ulcer healing.

Methods: Two-hundred and eleven patients with a duodenal ulcer and $H$. pylori infection were prospectively studied (mean age: $46 \pm 14$ years, $72 \%$ males). At endoscopy, biopsies were obtained from both gastric antrum and body (H\&E), and a ${ }^{13} \mathrm{C}$ breath test was also performed. Two different consecutive therapies with a proton pump inhibitor (PPI, omeprazole or lansoprazole) were administered: group A: PPI plus one antibiotic (amoxycillin or clarithromycin) for two weeks ( $n=62)$; group B: PPI plus two antibiotics (amocycillin/clarithromicina/metronidazole) for only one week $(n=149)$. Endoscopy and ${ }^{13} \mathrm{C}$ breath test were repeated one month after completing therapy. Eradication was defined as the absence of $H$. pylori by all diagnostic methods.

Results: Overall, $H$. pylori eradication was achieved in $68 \%$ of patients: group A: $34 \%$ (CI 95\%: 23-46\%); group B: $82 \%$ (76-88\%) (p < 0.001). In the multivariate analysis $H$. pylori eradication was the only variable which correlated with ulcer healing $\left(O R=14 ; \mathrm{CI}\right.$ : $6.7-29$; $\mathrm{chi}^{2}=49$; $\mathrm{p}<0.001$ ). Additional variables (age, sex, smoking, time of evolution of ulcer disease, ulcer size, and type of therapy) were not significantly correlated. Overall, healing ulcer was achieved in $74 \%$ of cases, but it was significantly higher in eradicated $(90 \% ; 85-95 \%)$ than in non-eradicated $(41 \% ; 29-52 \%)$ patients $(\mathrm{p}<0.001)$. Thus, in group B (PPI plus two antibiotics for $1 \mathrm{wk}$ ) and successful $H$. pylori eradication, the ulcer healing rate was $89 \%(83-94 \%)$.

Conclusion: H. pylori eradication accelerates ulcer healing, which represents an additional argument for employing eradication therapy in patients with duodenal ulcer disease. We also conclude that administering a PPI for 1 or 2 wks (only for the antibiotic administration period) - a simple and economic therapy - is enough to obtain ulcer healing, provided that $H$. pylori eradication is achieved.

\section{A:28 EFFECT OF THE ERRADICATION OF HELICOBACTER PYLORI IN PATIENTS WITH DUODENAL ULCER AFTER ONE YEAR'S FOLLOW UP}

M. García Montero ${ }^{1}$, A. Caballero Plasencia ${ }^{2}$, F. Martínez Salmerón ${ }^{3}$, F. Santalla Peciña ${ }^{4}$, M.D. Espinosa Aguilar ${ }^{1}$, M. López de Hierro ${ }^{1}$, J. Marín' ', M. Rodrigo Moreno'. ' Hospital Virgen de las Nieves. Granada; ${ }^{2}$ Hospital Universitario, Granada; ${ }^{3}$ Hospital Santa Ana, Motril, Granada; ${ }^{4}$ Hospital Axarquía, Vélez Málaga, Málaga

Objectives: Patients diagnosed with duodenal ulcer and with documented Helicobacter pylori infection were followed for one year. Treatment with omeprazol and clarithromycin led to healing of the ulcer. We then compared the clinical course in patients in whom $H$. Pylori was erradicated, and in those in whom the infection persisted.

Patients and Methods: Patients were diagnosed endoscopically with duodenal ulcer. Helicobacter pylori infection was considered to exist if the rapid urease test was positive and if either histological examination or culture of antral biopsy was also positive. Commercial tests (CLO-test and
JATROX test) were used. Cultures were done under standard conditions in chocolate agar medium, and histological observations were made in Giemsa-stained material. Sixty patients were treated with clarithromycin $500 \mathrm{mg}$ twice daily for 14 days plus omeprazol $20 \mathrm{mg}$ twice daily for 28 days. Twenty-four patients were treated with the same regimen of clarithromicine plus omeprazol for 14 rather 28 days. Four weeks ( $39 \pm 4$ days) after the end of treatment, endoscopic examination was repeated and antral biopsies were taken for rapid urease tests and histological examination or culture. Patients whose ulcer had healed were examinated 3, 6, 9 and 12 months later. If the ulcer had recurred or if the patient was asymptomatic at the 6- or 12-month follow-up, endoscopic examination and biopsy were repeated. The results between the two groups were compared with Fisher's exact test. The difference was considered significant when $p<0.001$.

Results: A total of 84 patients were examined endoscopically one month after antibiotic treatment had ended. Healing had occurred in 98.8\% (83/84). Helicobacter pylori was erradicated in $70.23 \%$ (59/84), but remained present in 25 patients $(29.76 \%$ ); in one of these patients the duodenal ulcer was not cured. After six months 54 of the patients in whom H. pylori was erradicated were examined again; relapse occurred in only one patient $(1.85 \%)$. Of the $20 \mathrm{H}$. pylori-positive patients examined, relapse was found in $8(40 \%)$. After 12 months, 48 patients in the first group were examined, and relapse was diagnosed in $2(4.16 \%)$. Relapse had occurred in 12 of the $18 \mathrm{H}$. pylori-positive patients $(72.22 \%$ ) we examined.

Conclusions: Patients with duodenal ulcer in whom H. pylori is erradicated had a significantly lower rate of relapse than patients in whom the bacterial infection persisted.

\section{A:29 DOES ERADICATION OF HELICOBACTER PYLORI DECREASE THE RISK OF MUCOSAL LESIONS IN PATIENTS TAKING NSAID?}

H. Kordecki, R. Kosik, P. Milkiewicz, D. Kubisa. M. Curie Hospital, Szczecin, Poland

The frequency of Helicobacter pylori (H.p.) infection in patients chronically treated with NSAID is nearly the same as in persons who have the same mucosal changes but do not take NSAID. Simultaneous application of NSAID markedly increases the frequency of mucosal lesions occurrence.

The aim of our study was to estimate the reccurency rate of mucosal lesions 8 months after the end of therapy in persons chronically taking NSAID. In the majority of patients eradication of $\mathrm{H}$. pylori was carried out. The remaining patients were treated with $\mathrm{H}-2$ blockers only.

Material and methods: Endoscopic examinations were performed with Olympus EVIS 100 equipment in 138 patients receiving chronically NSAID. In 95 persons (69\%) taking NSAID lesions like ulcers and erosions in the stomach and/or duodenum were found. In $63(66 \%)$ out of this group H.p. infection was diagnosed (rapid urease test and microscopical examination). However negative results were disclosed in 32 patients $(34 \%)$. Patients who had mucosal lesions in stomach or/and duodenum were treated with one of these three methods: 1 . ranitidine only $(R), 2$. colloidal bismuth with amoxicillin and metronidazole $(C B+A+M), 3$. omeprazole with amoxicillin and metronidazole $(\mathrm{O}+\mathrm{A}+\mathrm{M})$.

Results:

\begin{tabular}{|c|c|c|c|c|c|}
\hline \multirow{2}{*}{ Treatment } & \multirow[t]{2}{*}{ Patients } & \multicolumn{2}{|c|}{1 month after therapy } & \multicolumn{2}{|c|}{8 months after therapy } \\
\hline & & $\begin{array}{l}\text { healing } \\
\text { rate }\end{array}$ & $\begin{array}{l}\text { eradication } \\
\text { rate }\end{array}$ & $\begin{array}{l}\text { healing } \\
\text { rate }\end{array}$ & $\begin{array}{l}\text { eradication } \\
\text { rate }\end{array}$ \\
\hline $\begin{array}{l}R \\
C B+A+M \\
O+A+M\end{array}$ & $\begin{array}{l}12 \\
25 \\
26\end{array}$ & $\begin{array}{r}6(50 \%) \\
19(76 \%) \\
24(92 \%)\end{array}$ & $\begin{array}{r}2(17 \%) \\
16(64 \%) \\
24(92 \%)\end{array}$ & $\begin{array}{r}2(17 \%) \\
9(36 \%) \\
24(92 \%)\end{array}$ & $\begin{array}{c}0 \quad(0 \%) \\
7(28 \%) \\
23(88 \%)\end{array}$ \\
\hline
\end{tabular}

Conclusions: 1. The largest number of long-term-healing and eradication of $\mathrm{H}$.p. was obtained after treatment with $\mathrm{O}+\mathrm{A}+\mathrm{M}$. 2 . In our opinion eradication of H.p. in patients taking NSAID significantly decreases the number of recurrences of mucosal lesions in stomach and duodenum.

\section{A:30 HIGH PREVALENCE OF DUODENAL ULCER AND GASTRIC CANCER IN DYSPEPTIC PATIENTS IN SOUTH KOREA}

H.M. Malaty, J.G. Kim. D.P. Graham, D.Y. Graham. VA Medical Center and Baylor College of Medicine, Houston, TX, USA; Guro Hospital, Korea University College of Medicine, Seoul, Korea

Objective: To study the prevalence of peptic ulcer disease (PUD) and gastric cancer (GCA) in dyspeptic Koreans without a history of PUD or GCA. We also compared the results to the findings from Peru and Colombia where gastric cancer is common and duodenal ulcer (DU) is rare. It is believed that this pattern is the rule.

Methods: 867 patients, ages 20 to 81 , were studied within one year period at the Guro Hospital in Seoul. Each patient completed a detailed questionnaire and underwent endoscopy. Results: 867 patients were studied including 371 men (43\%) and $496(57 \%)$ women. 24\% (207) had PUD 
(active ulcer or scar) and 7\% (63) had GCA. DU was more common than GU or combined DU \& GU $(75 \%, 21 \%$, and $4 \%$, respectively). The M:F ratio was also higher in DU than GU (1.4:1 vs. 3.6:1). The mean age was similar for DU and GU patients ( $45 \pm 14$ vs. $48 \pm 12$ years). The $\mathrm{M} \cdot \mathrm{F}$ ratio for GCA was 2.9:1 with the mean age of $59 \pm 11$ years, which was significantly higher than the PUD patients $(p<0.01)$. Only $44(7 \%)$ of the 597 remaining patients had definite endoscopic abnormalities (e.g. esophagitis, duodenitis, or pyloric deformity). Conclusion: PUD and GCA are extraordinarily common diagnoses among dyspeptic Korean patients. In contrast to the findings from Peru and Colombia, DU was also common (i.e. the high frequency of GCA was not associated with a low rate of DU). Accordingly, the findings from Peru and Colombia can not be universalized. If cancer and/or DU $H p$ strains exist, they must circulate simultaneously at high frequency among Koreans. Korea may be the ideal country to investigate the relation between specific $H p$ strains and different $H p$ diseases.

\section{A:31 OXYNTIC GLAND AREA AND DENSITY OF PARIETAL CELLS AND ITS RELATIONSHIP TO ACID OUTPUT IN $H$. PYLORI-INFECTED DUODENAL ULCER PATIENTS}

S.S. Kim, I.S. Chung, J.Y. Choi, Y.S. Yang, D.H. Park, B.S. Kim. Catholic University Medical College, Seoul, Korea

Convincing evidence now exists that $H$. pylori has a pathogenic role in the development of active chronic gastritis and duodenal ulcer (DU). Unlike $H$. pylori-induced gastritis, the pathophysiology of $H$. pylori-induced DU is not clearly defined. It has been well known that patients with DU disease tend to secrete more acid than non-DU subjects. To secrete more acid, the density of parietal cells should be increased, or the oxyntic gland area of gastric mucosa should be well preserved. To investigate which of two postulations is more relevant to hyperacidity in $H$. pylori-infected DU patients, we examined the acid output (basal and pentagastrin-stimulated), the density of parietal cells (the number of parietal cells per unit area of the oxyntic gland), and the oxyntic area by Congo red chromoscopy in $H$. pylori-infected $20 \mathrm{DU}$ patients and 20 non-DU subjects.

Basal acid output of DU patients was about 5-fold higher than that of non-DU subjects ( $32.3 \pm 17.9$ vs. $6.1 \pm 5.6 \mathrm{mmol}, P<0.01)$. The maximal acid output and peak acid output of DU patients were also approximately 3-fold higher than those of non-DU subjects, respectively $(59.7 \pm 29.8$ vs. $18.8 \pm 18.9 \mathrm{mmol}, P<0.01 ; 73.9 \pm 40.1$ vs. $23.7 \pm 20.6 \mathrm{mmol}, P$ $<0.01$ ). In DU patients, although the density of parietal cells seemed to be higher than that of non-DU subjects $\left(579 \pm 197\right.$ vs. $\left.477 \pm 204 / \mathrm{mm}^{2}\right)$, the difference was not statistically significant. There was a significant difference in the width of oxyntic area between DU patients and non-DU subjects $(P<0.01) .85 \%$ of oxyntic area in DU patients was closed type, whereas $85 \%$ of non-DU subjects was open type. Peak acid output was well correlated with width of oxyntic area $(\mathrm{r}=0.568, P<0.01)$. In conclusion, Hyperacidity in $H$. pylori-infected duodenal ulcer patients is owing to rather well-preserved oxyntic gland area than density of parietal cells.

\section{A:32 ERADICATION OF H. PYLORI INFECTION IN PREVENTING DUODENAL ULCER BLEEDING: ONE YEAR INTERIM REPORT IN A PROSPECTIVE FIVE YEARS STUDY}

S. Salandin, N. Dal Bò, S.A. Grassi ${ }^{1}$, M. Ferrana, S. Kusstatscher, F. Vianello, A. Pilotto, M. Bortolon, F. Farinati, G. Battaglia ${ }^{2}$, F. Di Mario. Padua University, Italy; ${ }^{1}$ Marostica, Italy; ${ }^{2}$ Venice Hospital, Italy

Aim: The study was designed to evaluate the role of $\mathrm{Hp}$ infection associated with NSAIDs intake in duodenal ulcer bleeding. Methods: In an open five years prospective study (12-24 months) 50 consecutive patients Hp positive ( $37 \mathrm{M}, 13 \mathrm{~F}$; mean age 56 , range $27-68$ ) showing in the last 12 months at least one episode of bleeding duodenal ulcer, endoscopically documented, were enrolled. Eighteen subjects showed an intake of ulcerogenic drugs (NSAIDs+ve) causally related with bleeding episode. From each patient smoking habit, alcohol intake, blood group and family history of peptic ulcer were also recordered. The Hp status was assessed by means of urease test, hystology and serology. After an informed consent all patients received an eradication therapy (dual or triple regimen for 14 days); eradication rate was assessed 2 months after the end of the treatment as mentioned above. All subjects were followed-up by endoscopy (every 12 month and at any symptomatic recurrence) and clinical evaluation every six months. Results: Overall, in 35 out of the 50 patients $(70 \%) \mathrm{Hp}$ infection was eradicated (12 NSAIDs+ve and 23 NSAIDs-ve). Only one patient (Hp+ve/Nsaids-ve group) showed a bleeding episode at the fifth month of follow-up. Seven patients showed ulcer relapse ( 3 in Hp+ve/NSAIDs+ve and 4 in Hp+ve/NSAIDs-ve group); no $\mathrm{Hp}-\mathrm{ve}$ patient relapsed. No statistical differences were detected in Hp+ve vs $\mathrm{Hp}$-ve subjects as regards clinical and epidemiological parameters. Conclusions: These preliminary data seem to confirm the importance of $\mathrm{Hp}$ eradication in preventing bleeding duodenal ulcer, both in NSAIDs +ve and -ve groups.

\section{A:33 ONE YEAR PROSPECTIVE MULTICENTER STUDY AFTER ERADICATION IN HELICOBACTER PYLORI POSITIVE GASTRIC ULCER DISEASE}

F. Di Mario, G.A. Grasso ', S. Kusstatscher, M. Ferrana, N. Dal Bò, M. Bortolon, G. Tafner ${ }^{2}$, R. Marin ${ }^{3}$, A. Caroli ${ }^{4}$, S. Salandin, M. Cassaro, M. Rugge, G. Battaglia ${ }^{1}$. Padova, Italy; ${ }^{1}$ Venezia, Italy; ${ }^{2}$ Trento, Italy; ${ }^{3}$ Dolo, Italy; ${ }^{4}$ Montebelluna, Italy

Hp infection plays a different role in the pathofisiology of gastric (GU) and duodenal ulcer (DU). Since now, few studies are available on GU follow-up after Hp eradication. Therefore, the aim of this study was to evaluate ulcer relapse rate after Hp eradication in GU patients. Material and Methods: we enrolled in a prospective multicenter study 72 consecutive outpatients (mean age 49; range 26-79, M/F 38/34) referred for Hp positive GU. Hp status was evaluated by three different tests (histology, CLO test and serology). Study design: four endoscopies were performed during the follow-up: at baseline, two months after the end of a triple therapy treatment, at six and twelve months. Hp eradication was considered successful when both histology and CLO test resulted negative. Results: Over 72 patients 14 subjects remained $\mathrm{Hp}$ positive after the treatment. One out of the 58 eradicated pts become positive at six months. Seven GU relapses were observed ( 5 in $\mathrm{Hp}-$ and 2 in $\mathrm{Hp}+\mathrm{pts}$ ); in $2 / 5 \mathrm{Hp}-$ pts relapsed, a NSAIDs intake was documented. Conclusions: 1) Hp eradication in GU is related with a low relapse rate $(5 / 57) ; 2$ ) Contrary to the outcome observed in DU pts, only $2 / 14 \mathrm{Hp}+\mathrm{GU}$ relapsed during a twelve months follow-up; 3) Almost $50 \%$ of GU relapses in $\mathrm{Hp}$ - pts are related with NSAIDs assumption.

\section{A:34 SALIVARY AND GASTRIC EPIDERMAL GROWTH FACTOR (EGF) AND GASTRIC MUCOSAL EGF EXPRESSION IN DUODENAL ULCER (DU) PATIENTS BEFORE AND AFTER ERADICATION OF HELICOBACTER PYLORI (HP)}

P.C. Konturek ${ }^{1}$, A. Bobrzynski ${ }^{2}$, S.J. Konturek ${ }^{2}$, G. Faller, Ch. Klingler ${ }^{1}$, T. Kirchner, E.G. Hahn ${ }^{1} .{ }^{1}$ Dept. Med. I and Inst. Pathol., Univ. Erlangen, Germany; ${ }^{2}$ Inst. Physiol. Jagiell. Univ. Med. Sch. Krakow, Poland

EGF is released mainly by salivary glands and promotes gastric mucosal growth and repair but the influence of $\mathrm{Hp}$ infection on EGF release and its mucosal expression have not been evaluated. In this study, basal and pentagastrin-induced salivary and gastric luminal release of EGF (radioimmunoassay) as well as gastric mucosal expression of EGF (immunohistochemistry and RT-PCR) have been examined. $10 \mathrm{Hp}$-negative (by ${ }^{14} \mathrm{C}$-urea breath test) controls and $20 \mathrm{Hp}$-positive active duodenal ulcer (DU) patients were tested before and 4 weeks after 2 week triple therapy (amoxicillin $500 \mathrm{mg}$ qd, metronidazole $500 \mathrm{mg}$ bd and omeprazole $20 \mathrm{mg}$ bd). There was no difference in basal salivary and gastric luminal EGF contents between healthy controls and DU patients. Infusion of pentagastrin (2 $\mathrm{mg} / \mathrm{kg}-\mathrm{h}$ ) raised by 3 folds salivary and gastric luminal concentrations and outputs of EGF both in control and DU subjects but following successful eradication of gastric $\mathrm{Hp}$ (confirmed by histology and culture of endoscopic biopsy samples) and complete healing of DU, there was 3-4 fold higher gastric EGF release in basal state and after pentagastrin than before the triple therapy. Salivary basal and pentagastrin-stimulated EGF was not significantly affected by the triple therapy and $\mathrm{Hp}$ was detected in gingival pockets in 18 out of $20 \mathrm{DU}$ patients using $\mathrm{Hp}$ culture and PCR technique. Gastric mucosal EGF expression was negligible in healthy controls but was 2-4 times higher in DU patients and triple therapy had no influence on this enhanced expression. We conclude that (1) the stomach itself is capable to release large amounts of EGF that is augmented by pentagastrin, (2) gastric $\mathrm{Hp}$ eradication by triple therapy results in DU healing and further increase in gastric luminal EGF release and mucosal EGF expression but does not affect salivary EGF release possibly due to the failure to eradicate oral $\mathrm{Hp}$.

\section{A:35 PREVALENCE OF HELICOBACTER PYLORI AND ASANSAID USE IN PATIENTS WITH BLEEDING PEPTIC ULCER}

L. Søndergård, A. Lassen, O.B. Schaffalitzky de Muckadell. Odense University Hospital, Odense, Denmark

Aim: To investigate the $H$. pylori status in bleeding and non bleeding peptic ulcer patients.

Patients: 88 patients with bleeding and 90 patients with non bleeding endoscopically verified peptic ulcer were studied.

Methods: $H$. pylori infection was detected by ${ }^{13} \mathrm{C}$ Urea breath test and a structured interview was performed simultaneously.

Results: Patients with bleeding duodenal ulcer were less frequently infected with $H$. pylori $(35 / 58-60 \%)$, than patients with non bleeding 
duodenal ulcer $(47 / 55-85 \%)\left(\chi^{2}: \mathrm{p}<0.01\right)$. More patients with bleeding duodenal ulcer (35/58), had taken non-steroidal anti-inflammatory drugs during the last month than patients with non bleeding duodenal ulcer $(12 / 55)\left(\chi^{2}: \mathrm{p}<0.05\right)$. Analysis stratified for the use of non-steroidal antiinflammatory drugs showed similar results. The lower $H$. pylori frequency in bleeding patients was most pronounced in patients that did not use non-steroidal anti-inflammatory drugs $(12 / 23 \mathrm{H}$. pylori positive/bleeding patients versus $38 / 43 \mathrm{H}$. pylori positive/non bleeding patients) $\left(\chi^{2}: \mathrm{p}<\right.$ $0.01)$.

There was no difference in $H$. pylori status for patients with bleeding and patients with non bleeding gastric ulcer. More patients with bleeding gastric ulcer (23/30) than patients with non bleeding gastric ulcer $(18 / 35)$ had used non-steroidal anti-inflammatory drugs the last month $\left(\chi^{2}: \mathrm{p}<\right.$ 0.05).

Conclusion: Patients with bleeding duodenal ulcer have a lower frequency of $H$. pylori infection than patients with a non complicated duodenal ulcer. This difference is not explained by the frequent use of non-steroidal anti-inflammatory drugs in these patients.

\section{A:36 HELICOBACTER PYLORI (HP) INFECTION, CIGARETTE SMOKING AND ALCOHOL CONSUMPTION IN REFLUX OESOPHAGITIS}

J. Lee, N. Breslin, C. O'Morain. Dept. of Gastroenterology, Meath/Adelaide Hospitals, Dublin, Ireland

Introduction: It is generally accepted that oesophagitis results from abnormal exposure of the oesophageal mucosa to refluxed gastric contents i.e. acid and pepsin. HP infected patients (particularly those with duodenal ulceration) have higher gastrin, acid and pepsin output, thus increasing their vulnerability to develop reflux oesophagitis. In this study the relationship between HP status, cigarette smoking, alcohol consumption and reflux oesophagitis was examined.

Methods: Consecutive patients with symptoms of gastro-oesophageal reflux (GOR) and evidence of oesophagitis at endoscopy were considered. Patients with previous eradication therapy, current antisecretory drugs or antibiotics, or current endoscopic diagnoses other than GOR, i.e. DU, GU, etc. were excluded. The grade of oesophagitis was determined (Savary-Miller classification) and gastric mucosal biopsies were obtained for HP determination (rapid urease test, histology and culture). Alcohol consumption and cigarette smoking habits were recorded.

Results: 218 patients (114 male) were included.

\begin{tabular}{llllll}
\hline & $\begin{array}{l}\text { GOR 1 } \\
(\mathrm{n}=145)\end{array}$ & $\begin{array}{l}\text { GOR 2 } \\
(\mathrm{n}=42\end{array}$ & $\begin{array}{l}\text { GOR 3 \& 4 } \\
(\mathrm{n}=21)\end{array}$ & $\begin{array}{l}\text { Barretts } \\
(\mathrm{n}=10)\end{array}$ & $\begin{array}{l}\text { Total } \\
(\mathrm{n}=218)\end{array}$ \\
\hline HP +ive & $39 \%$ & $38 \%$ & $28.5 \%$ & $50 \%$ & $38 \%$ \\
HP -ive & $61 \%$ & $62 \%$ & $71.5 \%$ & $50 \%$ & $62 \%$ \\
\hline
\end{tabular}

Overall HP was present in $38 \%$ of patients and no significant difference was found between the different grades of oesophagitis. Both cigarette smoking and alcohol consumption were more common in male patients i.e. $61 \%$ vs. $46 \%(\mathrm{p}<0.05)$ and $82.5 \%$ vs. $58 \%(\mathrm{p}<0.001)$ respectively. No significant difference between HP +ive and HP -ive patients was shown in either case.

Conclusion: Our results do not support a role for $\mathrm{H}$. pylori in the development of reflux oesophagitis independent of other endoscopic diagnoses. They do support a role for both cigarette smoking and alcohol, particularly in male patients, but independent of HP status.

\section{A:37 HELICOBACTER PYLORI (HP), CORONARY HEART DISEASE (CHD) AND PLASMA FIBRINOGEN: IS THERE A CAUSAL LINK?}

G. Treiber, E. Schneider, C. Adolph, S. Lenferink. Robert-Bosch-Hospital, Auerbachstr. 110, D-70376 Stuttgart, Germany

Former studies indicated that there may be a link between HP-infection and the development of CHD by raised fibrinogen. Unfortunately, they were either too small in study size, or retrospective, or classified CHD only by clinical diagnosis or did not consider other inflammatory reasons while measuring plasma fibrinogen. In our prospective study we tried to avoid these challenges by including 317 patients referred to our hospital for routine-coronarangiografie. HP-status was measured serologically test (Orion diagnostics). Coronary status as well as clinical and routine laboratory parameters were determined by different (blinded) investigators. Patients were considered to suffer from CHD by having a stenosis $>70 \%$ of at least one vessel. Values of less than $350 \mathrm{mg} / \mathrm{dl}$ fibrinogen in plasma, less than $1 \mathrm{mg} / \mathrm{dl} \mathrm{C}$ reactive protein, less than 10000 leucocytes or a BSR of less than 20 in the first hour were regarded as normal. Results: From total 317 patients 160 were HP positive, 245 had CHD and 104 raised plasma fibrinogen. As expected, the HP+ group had more often a history of peptic ulcer than the HP- one (22 vs $8 \%$ ). The CHD- group included fewer prevalences of coronary risk factors such as nicotine (21 vs $32 \%$ ) systemic hypertension (51 vs $60 \%$ ), diabetes mellitus ( 13 vs $20 \%$ ), history of familiar CHD (13 vs $25 \%$ ). Mean time of onset of angina (19.7 vs 51.6 months) was lower as was mean number of myocardial infarctions $(0.04$ vs 0.71 ). The group with raised plasma fibrinogen had significantly higher elevated CrP (1.21 vs $0.56 \mathrm{mg} / \mathrm{dl})$, BSR (25 vs $10.8 \mathrm{~mm} / 1 . \mathrm{h}$ ) and leucocytes ( 7426 vs 7094 ). There was a not significant trend between elevated levels of cholesterine, plasma triglycerides, fibrinogen and CHD. Otherwise, CHD+ and CHD- groups had comparable parameters. We found no correlation between HP-infection and CHD, including fibrinogen or not.

\begin{tabular}{lllllll}
\hline $\mathrm{n}=$ & $\mathrm{CHD}+$ & $\mathrm{CHD}-$ & $\mathrm{CHD}+\mathrm{Fib} \uparrow$ & $\mathrm{CHD}-\mathrm{Fib} \uparrow$ & $\begin{array}{l}\mathrm{CHD}+\text { isol. } \\
\text { Fib } \uparrow\end{array}$ & $\begin{array}{l}\text { CHD-isol. } \\
\text { Fib } \uparrow\end{array}$ \\
\hline $\mathrm{HP}+$ & 127 & 33 & 49 & 6 & $21^{*}$ & 1 \\
$\mathrm{HP}-$ & 118 & 39 & 42 & 7 & $11^{*}$ & 4 \\
\hline
\end{tabular}

*Differences between the two groups $p=0.05$ (chi-square-test)

However, a subgroup of patients with raised plasma, fibrinogen without an explanation for an other inflammatory process (isol. Fib. $\uparrow$ ) may be at a higher risk of developing CHD from HP-infection. An intervention part (influence of successful HP-eradication therapy on lowering fibrinogen in this subgroup) is ongoing, results are presented at the meeting.

\section{A:38 EMERGENCY CARE UNIT PATIENTS WHO ARE ANTI-Cag-A POSITIVE ARE AT VERY HIGH RISK FOR DUODENAL ULCER}

A. Morgando, P. Sanseverino ${ }^{1}$, C. Moiraghi, F. Molino, G. Pugliese ${ }^{2}$, A. Ferrari ${ }^{2}$, V. Gai, A. Ponzetto ${ }^{2}{ }^{1}$ Dpt Emergency, Micro, Molinette, Torino, Italy; ${ }^{2}$ Dpt Emergency, GI, Molinette, Torino, Italy

Duodenal ulcer (DU) is a chronic disease linked to Helicobacter pylori infection. Cytotoxic strains of $\mathrm{H}$. pylori pose a higher risk of DU, and can easily detected by serological methods: either immunoblot or enzymelinked immune assay (ELISA). We identified patients infected by strains of $\mathrm{H}$. pylori expressing the cytotoxin-associated gene A (cag-A) protein by means of in house ELISA which employs a recombinant purified fragment of the cag-A protein (gift of Dr A Covacci, Iris Biocine, Siena).

Of 585 patients presenting at the Emergency Care of our Hospital from 16 through 30 august 1994, 17 had an acute duodenal ulcer. Serological pattern of $\mathrm{H}$. pylori infection is reported in table

Acute duodenal ulcer and $\mathrm{H}$. pylori serology

\begin{tabular}{|c|c|c|}
\hline \multicolumn{2}{|c|}{ Anti-H. pylori (pos) } & \multirow{2}{*}{$\begin{array}{l}\text { Anti-H. pylori (neg) } \\
\text { ulcer/total }\end{array}$} \\
\hline $\begin{array}{l}\text { Cag-A (+)ve } \\
\text { ulcer/total }\end{array}$ & $\begin{array}{l}\text { Cag-A (-)ve } \\
\text { ulcer/total }\end{array}$ & \\
\hline $13 / 121$ & $4 / 223$ & $0 / 241$ \\
\hline
\end{tabular}

Duodenal ulcer was present solely among patients infected by H. pylori. Patients infected by Cag-A positive strains at at very high risk of acute duodenal ulcer. 